\title{
DigiPrime: Digital Platform for Circular Economy in Cross-Sectorial Sustainable Value Networks ${ }^{\dagger}$
}

\author{
Elena Mossali ${ }^{1}$, Marco Diani ${ }^{2}$ and Marcello Colledani ${ }^{2, *}$ \\ 1 STIIMA CNR, Institute of Intelligent Industrial Technologies and Systems for Advanced Manufacturin- \\ National Research Council, Via Alfonso Corti 12, 20133 Milan, Italy; elena.mossali@stiima.cnr.it \\ 2 Department of Mechanical Engineering, Politecnico di Milano, Via La Masa 1, 20156 Milan, Italy; \\ marco.diani@polimi.it \\ * Correspondence: marcello.colledani@polimi.it; Tel.: +39-02-2399-8587 \\ + Presented at the Sustainable Places 2020, Online, 28-30 October 2020.
}

Published: 23 December 2020

\begin{abstract}
Circular Economy is the solution for the current environmental crisis, representing a huge economic opportunity to build new sustainable businesses. However, many barriers need to be faced for its implementation at industrial scale-firstly, the lack of data sharing between the different stakeholders of product value-chains. The DigiPrime project is an EU-funded Innovation Action aimed at developing and demonstrating a digital platform with services able to unlock innovative cross-sectorial business models for the remanufacturing and recycling of target valueadded products. In this paper, the concept behind the DigiPrime project is reported, with a particular focus on the construction sector.
\end{abstract}

Keywords: digital platform; circular economy; cross-sectorial value-chains; circular services; construction; composites; open calls

\section{Introduction}

Starting with the Industrial Revolution of the second half of the 19th century, the global economy was based on fossil fuel and raw material extraction, with the assumption that resources were abundant, available, easy to source and cheap to dispose. This linear economic trend made society progressively detach from the natural environment, in particular after the diffusion of new business models, such as mass production, consumerism and disposability [1]. Furthermore, the take-usediscard concept has led humanity to consume more resources than nature can regenerate, depleting natural ecosystems and emitting unbearable amounts of $\mathrm{CO}_{2}$ into the atmosphere. Currently, human demand for natural raw materials is projected to overcome nature's ability to regenerate by about $75 \%$ by 2020 , and by $100 \%$ by 2030 . Globally, the demand for materials has become ten times bigger since the beginning of the 20th century and it will double its value again by 2030 [2].

Nowadays, forced by the stricter regulations and increased awareness, the transition from this traditional value-chain towards more sustainable models goes through the concept of Circular Economy (CE), aimed at disrupting the linear consumption model by employing closed- and openloop cycles. In this way, the regeneration of End-of-Life (EoL) products into new products, components or raw materials through reuse, remanufacturing and recycling processes reduces waste and boosts economic, social and technological prosperity with the creation of new cross-sectorial business opportunities [3]. It was reported, for example, that in Europe, India and China a CE adoption could reduce Greenhous Gases emissions by $22-44 \%$ in 2050 , if implemented in the construction, mobility, food, electronics and textile sectors [4]. 
However, many barriers need to be faced for this transition. The lack of product data sharing along the whole value-chain could make the EoL processes technically and economically unfeasible due to the non-optimal set up of the equipment or the need for additional steps to extract the required information. Furthermore, the lack of standards regulating the second life and the poor market acceptability of the recovered products, such as consumers' perception that recycled materials are equivalent to lower quality, strongly limit the industrial attractiveness of business models based on remanufacturing and/or recycling [5]. Even if some best practices have been demonstrated, stronger external barriers prevent $\mathrm{CE}$ implementation and individual circular companies are pointless if the associated supply chains and infrastructures maintain a linear approach [6].

In order to facilitate the transition towards CE and to solve these issues, the DigiPrime project focuses on data sharing between stakeholders, not only at sectorial value-chain level but also among different sectors, in order to allow the exploitation of products' residual properties in less demanding applications. A typical example is the automotive lithium-ion battery packs contained in electric vehicles: e-mobility batteries are removed from the cars when they reach $80 \%$ of nominal properties, but their residual value could easily be used in batteries for energy storage from renewable sources, extending their use phase up to an additional twenty years. To boost the collaboration of the different stakeholders of the value chain, DigiPrime started from the analysis of existing platforms and tools in order to allow their scale up at industrial level and their interoperability, demonstrating the economic, environmental and social feasibility of these new circular business models at a European scale.

\section{DigiPrime Project}

The DigiPrime project was funded by the H2020 program, in the call H2020-DT-ICT-07-20182019 "Digital Manufacturing Platforms for Connected Smart Factories" [7]. The activities, started in January 2020, will last 4 years with a total funding of EUR 16,000,000 and are performed by a Consortium constituted by 36 partners, representing 11 European countries (Figure 1a) divided into six different manufacturing sectors. The aim of the project is the development of a digital platform offering services able to boost the transition towards a Circular Economy. The idea is to overcome the current barriers (e.g., information asymmetry among value-chain stakeholders) in order to unlock new circular business models based on the data-enhanced recovery and re-use of functions and materials with a cross-sectorial approach, allowing a more sustainable and profitable management of high value-added End-of-Life products.

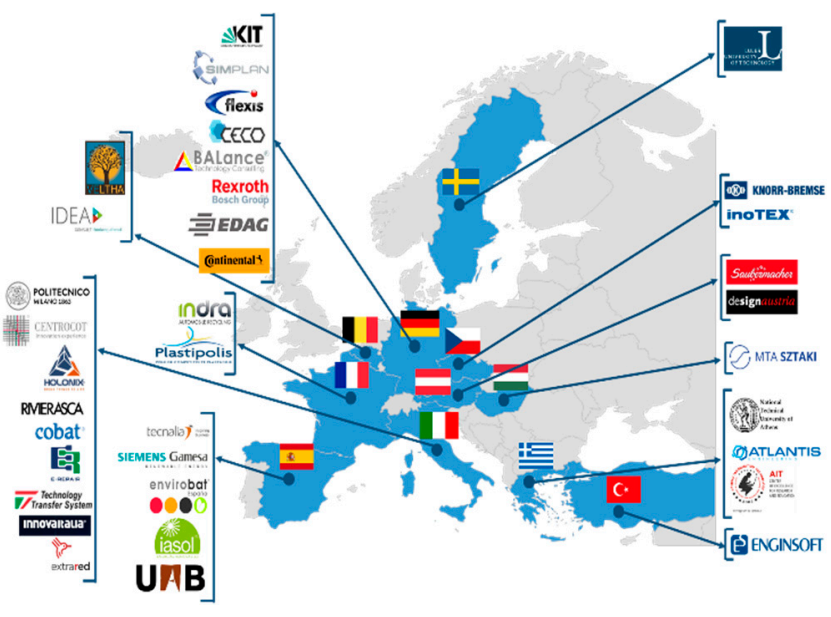

(a)

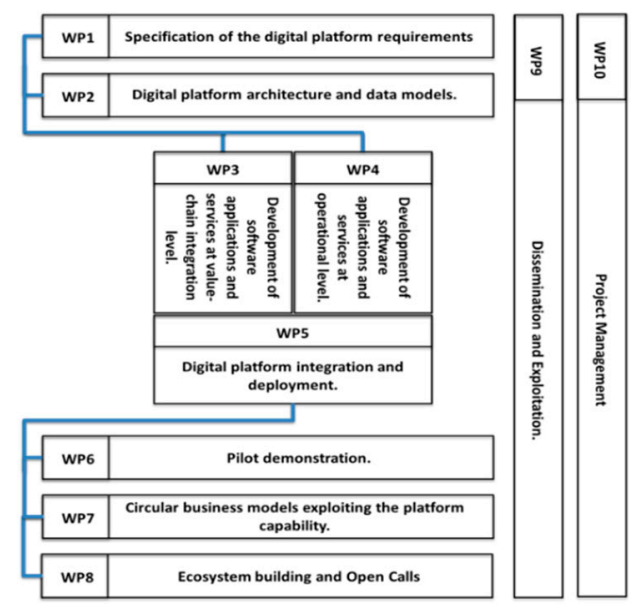

(b)

Figure 1. (a) DigiPrime Consortium; (b) General structure of DigiPrime project highlighting workpackages (WPs) interconnections.

The whole structure of the project (Figure $1 \mathrm{~b}$ ) is strongly oriented to the industrial demonstration of solutions. The first workpackages (WPs), in fact, dedicated to the definition and development of 
services, will take just the first two years, then they will be implemented and validated in real industrial environments, demonstrating their cross-sectorial potentiality.

\subsection{Platform Architecture}

The first activities of the DigiPrime project are focused on the definition and development of platform requirements and architecture. In particular, DigiPrime is based on a multi-node federation structure, where different value-chain stakeholders (e.g., manufacturers, recyclers, end-users) could interact at different levels among sectors (e.g., automotive, machinery, construction). According to the specific service requirements, the platform will mix a centralized and de-centralized approach, in some cases acting as a central point for the collection of data, and in others allowing direct contact between the actors, through block-chain technology, thus increasing platform trustworthiness. Finally, the integration of a semantic data infrastructure and a data policy framework will ensure easy and fast research of needed information and their protection across the platform.

The 16 developed services, available for the different stakeholders from the platform, are classified into two different types and are reported in the following subsections.

\subsubsection{Value-Chain Oriented Services}

The value-chain oriented services (VCO) are horizontal and connect stakeholders coming from different nodes (i.e., sectors):

- Data sharing management

- Product co-creation

- Life Cycle Assessment and Cost (LCA-LCC) for eco-design

- Demand-supply matching

- Reverse logistic configuration

- Cross-regional value-chain identification

- Material flow monitoring

- Circular Innovation hubs integration

- Legislation support

An example of VCO service is the demand-supply matching tool, where the suppliers of postuse products (such as collection centers) interact with de- and remanufacturing actors in order to negotiate the needs of material according to the current availability, the residual value, etc. The service allows the sharing of information and collaboration among stakeholders acting in different sectors.

\subsubsection{Operational Services}

Operational services (OS), instead, are vertical and dedicated to specific actors of the value-chain that could manage and optimize their processes to increase their profitability:

- In-use phase monitoring

- Product conditions prediction

- De- and remanufacturing decision support system

- De- and remanufacturing digital twin

- Demand and supply forecasting

- Circular production planning

- Material testing and certification

An example of OS is the material testing and certification tool, which is able to support the identification of the proper testing and certification procedure for the marketization of remanufactured or recovered products according to the specific secondary application. 


\subsection{Pilots}

All the developed services will be demonstrated through six DigiPrime Pilots (Figure 2). The first Pilots represent innovative cross-sectorial circular value-chains related to four main target products and materials, respectively: (i) lithium-ion batteries, (ii) mechatronics and electronics components, (iii) composites and techno-polymers and (iv) textile products. The Consortium partners, representing different actors of the value-chain of one of these targets, will validate the effectiveness of services in an industrial environment, testing their interoperability with pre-existing individual Information and Communication Technology (ICT) tools and the selected data populating the platform.

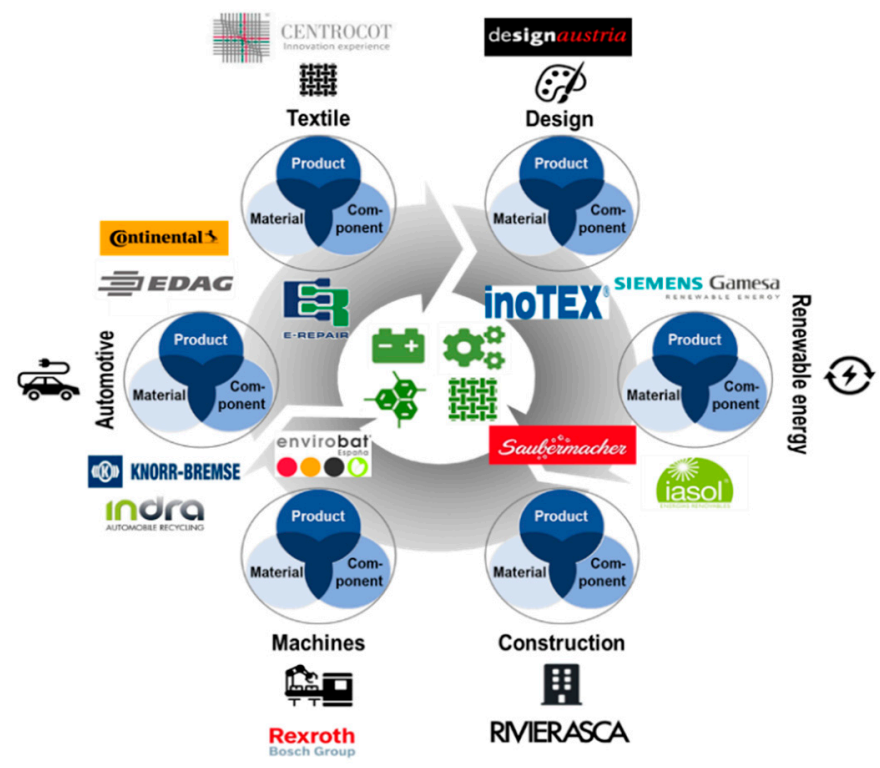

Figure 2. DigiPrime Pilots visualization.

The last two strategic Pilots, instead, are aimed at boosting a European transition towards CE beyond the value-chains already identified. Pilot 5, in particular, is focused on the identification and establishment of innovative value-chains intersecting traditional business sectors through a scalable and replicable framework (i.e., Screen methodology [8,9]). Pilot 6, finally, will support and integrate Circular Innovation Hubs, such as Vanguard initiative, in order to demonstrate the feasibility of sustainable-oriented solutions before industrial companies privately invest into innovative CEoriented processes.

\section{DigiPrime and the Construction Sector}

Pilot 3 on composite and techno-polymer circular solutions (Figure 3) has different use-cases for the demonstration of DigiPrime services concerning the construction sector. The strong crosssectorial approach is the added-value of the pilot: in the case of automotive and renewable energy, in fact, the requirements are highly demanding in terms of mechanical and physical properties and a closed loop recycling approach is not feasible, but the interesting material residual properties could be easily exploited in other applications. DigiPrime supports this strategy, allowing the interaction and collaboration between stakeholders of traditionally different value-chains. 


\begin{tabular}{|c|c|c|c|c|}
\hline \multicolumn{5}{|c|}{ Pilot 3: Composites and Techno-polymers } \\
\hline \multicolumn{5}{|c|}{ Involved sectors: automotive, construction, renewable energy, design products } \\
\hline \multicolumn{5}{|c|}{$\begin{array}{l}\text { Components: chassis, clutch pedal, wheel covers, rear panel, seat structure, front-end, leaf spring, } \\
\text { roof, dashboard, bumper, fender, wind blades, design products, roof tops }\end{array}$} \\
\hline \multicolumn{5}{|c|}{ Industrial Partners: EDAG, RIV, SGRE, DA, COT, SDAG } \\
\hline Use-Case & CE strategy & Involved partners & Input sectors & Output Sectors \\
\hline 3.1 & \begin{tabular}{|l|} 
Recycling \\
\end{tabular} & EDAG, RIV, COT, SDAG & Automotive & Construction \\
\hline 3.2 & \begin{tabular}{|l} 
Recycling \\
\end{tabular} & EDAG, DA, COT, SDAG & Automotive & Design \\
\hline 3.3 & \begin{tabular}{|l} 
Recycling \\
\end{tabular} & EDAG, SDAG, SGRE, COT & Renewable energy & Automotive \\
\hline 3.4 & \begin{tabular}{|l} 
Recycling \\
\end{tabular} & RIV, SGRE, COT, SDAG & Renewable energy & Construction \\
\hline 3.5 & \begin{tabular}{|l} 
Recycling \\
\end{tabular} & SGRE, DA, SDAG & Renewable energy & Destgn \\
\hline 3.6 & \begin{tabular}{|l} 
Recycling \\
\end{tabular} & RIV, SDAG & Construction & Construction \\
\hline 3.7 & \begin{tabular}{|l} 
Recycling \\
\end{tabular} & DA, SDAG & Thesign & Uesign \\
\hline 3.8 & \begin{tabular}{|l} 
Recycling \\
\end{tabular} & RIV, DA, SDAG & Construction & Design \\
\hline
\end{tabular}

Figure 3. Pilot 3 use-cases.

The ideal circular value-chain for Pilot 3 is reported in Figure 4, where waste is mechanically or thermally recycled to obtain new products or secondary raw materials.

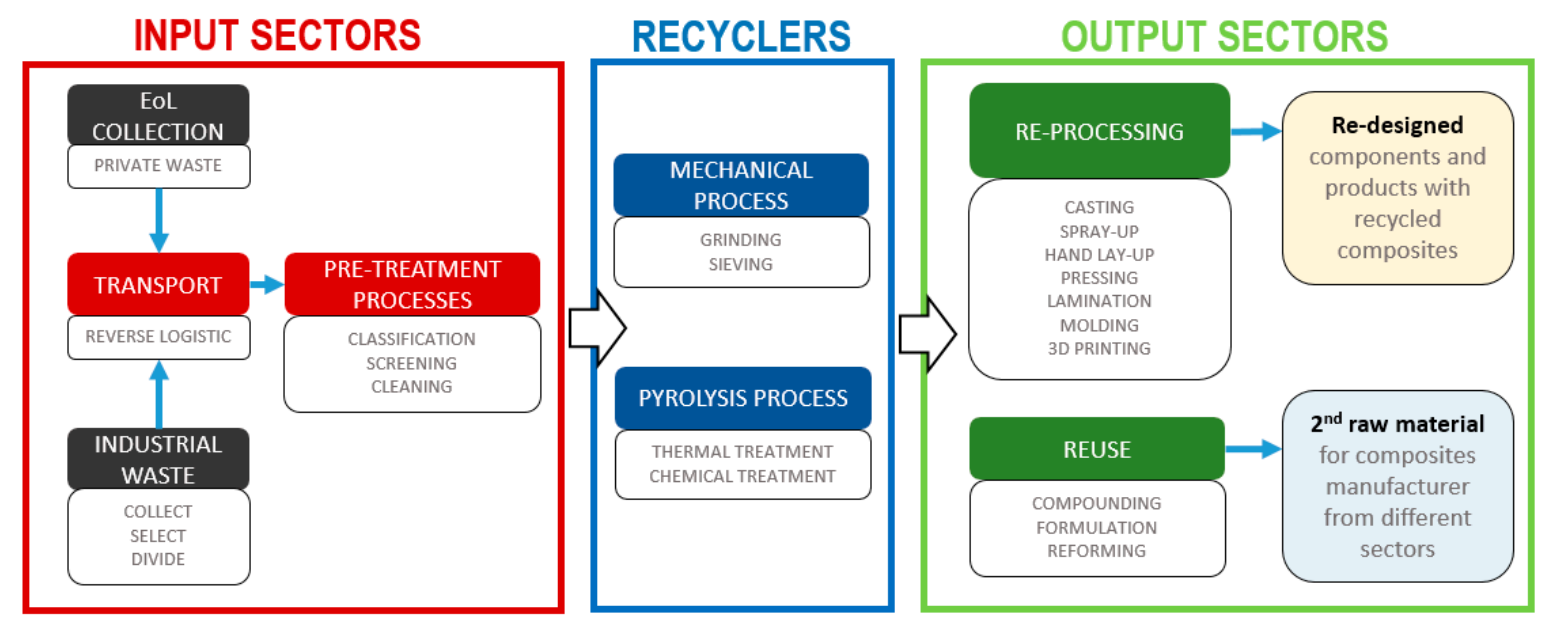

Figure 4. Ideal circular value-chain for composites and techno-polymer products.

Currently, only a few examples in Europe tried to implement this circular model at industrial scale, limited to selected inputs, such as their own manufacturing waste. The major challenge in this case is to also recycle End-of-Life products (e.g., wind blades, automotive components), whose compositional features are usually unknown. Moreover, the lack of information is not the unique barrier: the technical and economic feasibility of recycling processes is not fully demonstrated yet. For example, the traditional pyrolysis applied to glass fiber reinforced products is too expensive and causes the degradation of the fibers, strongly limiting their final reusability.

The implementation of DigiPrime services is aimed at optimizing processes and properties through a more effective sharing of information, at ensuring market penetration in terms of quantity and quality of products and at boosting the collaboration between value-chain actors for the supply of materials at different stages. Currently, in fact, no collection centers or centralized points of Endof-Life products to converge the material are established, and this strongly limits the availability and stable supply of waste for recycling.

In particular, construction is present in two use-cases as an input sector. End-of-Life products used in buildings, such as facade panels, covering sheets, piping, etc., are dismantled, recycled and used again in secondary applications thanks to the implementation of DigiPrime services aimed at improving the dismantling and sorting processes and the recycling treatments. As an output sector, instead, construction is present in three different use-cases: the recycled materials coming from different applications are used for the manufacturing of new products and components for buildings. A roof sheet, for example, will be produced from a wind blade thanks to the collaboration between 
stakeholders, unlocking relevant information such as the chemical composition of the wasted product, the residual mechanical properties and/or their variation in space (e.g., the percentage of fibers in blades changes in the function of the distance from the rotor).

\section{Open Calls}

Although the Pilots are addressed to map different value-chains, many others could be supported by the DigiPrime project. In order to extend the platform validation, in the third year of the project two Open Calls will be launched (Table 1). These will be aimed at identifying links among different sectors in new streams and implementing additional services customized for current industrial needs. The Open Calls will give funding to 12-17 proposals for a total amount of two million euros. Small-Medium Enterprises (SMEs) or small consortiums, also involving research or academia organizations, could participate.

Table 1. DigiPrime competitive Open Calls.

\begin{tabular}{|c|c|c|c|c|}
\hline Call & Obj & \multicolumn{2}{|c|}{ Indicative Dates } & Budget \\
\hline $\begin{array}{c}\text { TYPE A } \\
\text { Development of new } \\
\text { operational services } \\
\end{array}$ & $\begin{array}{ll}\text { - } & \text { Validate expandability } \\
\text { - } & \text { Complement existing Pilots } \\
\text { - } & \text { Expand DigiPrime solutions portfolio }\end{array}$ & $\begin{array}{l}\text { Launch: } \\
\text { APR } 2022\end{array}$ & $\begin{array}{l}\text { Closure: } \\
\text { JUN } 2022\end{array}$ & $\begin{array}{c}\text { TOT:1 M€ } \\
(100-150 \mathrm{~K})\end{array}$ \\
\hline $\begin{array}{c}\text { TYPE B } \\
\text { Development of Pilots } \\
\text { in new sectors }\end{array}$ & $\begin{array}{l}\text { - } \text { Validate DigiPrime in new areas } \\
\text { - } \quad \text { Demonstrate cross-border pilots } \\
\text { - }\end{array}$ & $\begin{array}{l}\text { Launch: } \\
\text { NOV } 2022\end{array}$ & $\begin{array}{l}\text { Closure: } \\
\text { JAN } 2023\end{array}$ & $\begin{array}{c}\text { TOT: } 1 \mathrm{M} € \\
(150-200 \mathrm{~K})\end{array}$ \\
\hline
\end{tabular}

\section{Conclusions}

The overall ambition of the DigiPrime project is to boost the systematic development and implementation of cross-sectorial circular value-chains in Europe by exploiting the platform capabilities and the related services, thus solving the current information asymmetry hindering the transition to circular business. The demonstration of DigiPrime services and capabilities will be performed through 6 Pilots, where Pilot 3 is dedicated to composites and techno-polymers coming from the automotive, renewable energy, design and construction sectors. Construction, in particular, currently suffers from a lack of data sharing and a discontinuous and unstructured material flow, strongly limiting the recycling opportunities of End-of-Life products. The validation of the DigiPrime platform will allow to overcome the existing barriers for the transition to a Circular Economy. Through the launch of competitive Open Calls, the project aims at extending developed services and solutions to additional cross-sectorial value-chains.

Author Contributions: Conceptualization, E.M. and M.D.; writing - original draft preparation, E.M.; writingreview and editing, E.M. and M.D.; supervision, M.C.; project administration, M.C. All authors have read and agreed to the published version of the manuscript.

Funding: The DigiPrime project has received funding from the European Union's Horizon2020 research and innovation program under grant agreement n. 873111.

Acknowledgments: We acknowledge Giacomo Bonaiti of Rivierasca S.P.A for the support in the analysis of current situation for construction sector and the whole DigiPrime Consortium.

Conflicts of Interest: The authors declare no conflict of interest.

\section{References}

1. Lieder, M.; Rashid, A. Towards circular economy implementation: a comprehensive review in context of manufacturing industry. J. Clean. Prod. 2016, 115, 36-51.

2. European Commission. Global Demand for Resources. Available online: https://ec.europa.eu/knowledge4 policy/foresight/topic/aggravating-resource-scarcity/global-demand-resources-materials_en (accessed on 22 December 2020). 
3. Bocken, N.M.; De Pauw, I.; Bakker, C.; van der Grinten, B. Product design and business model strategies for a circular economy. J. Ind. Prod. Eng. 2016, 33, 308-320.

4. Ellen MacArthur Foundation, Completing the Picture: How the Circular Economy Tackles Climate Change (2019). Available online: www.ellenmacarthurfoundation.org/publications (accessed on 22 December 2020).

5. Ritzén, S.; Sandström, G.Ö. Barriers to the Circular Economy-Integration of Perspectives and Domains. Procedia CIRP 2017, 64, 7-12.

6. Kirchherr, J.; Hekkert, M.; Bour, R.; Huijbrechtse-Truijens, A.; Kostense-Smit, E.; Muller, J. Breaking the Barriers to the Circular Economy. 2017. Available online: https://www.uu.nl/sites/default/files/breaking_the_barriers_to_the_circular_economy_white_paper_web. pdf (accessed on 22 December 2020).

7. CORDIS EU Research Results. Available online: https://cordis.europa.eu/project/id/873111/it (accessed on 22 December 2020).

8. Available online: http://www.screen-lab.eu/ (accessed on 22 December 2020).

9. CORDIS EU Research Results. Available online: https://cordis.europa.eu/project/id/730313 (accessed on 22 December 2020).

Publisher's Note: MDPI stays neutral with regard to jurisdictional claims in published maps and institutional affiliations.

(C) 2020 by the authors. Licensee MDPI, Basel, Switzerland. This article is an open access article distributed under the terms and conditions of the Creative Commons Attribution (CC BY) license (http://creativecommons.org/licenses/by/4.0/). 